\title{
Investigação-Formação-Ação em Ciências: Um Caminho Para Reconstruir a Relação Entre Livro Didático, o Professor e o Ensino
}

\author{
Research-Formation-Action in Science: A Way to Rebuild the elationship \\ Between Didactic Book, Teacher and Teaching
}

Kélli Renata Corrêa de Mattos (kellic.mattos@gmail.com)

Universidade Federal da Fronteira Sul (UFFS)

\begin{abstract}
Resumo:
Esta resenha trata do livro: "Investigação-Formação-Ação em Ciências: um Caminho para Reconstruir a Relação entre Livro Didático, o Professor e o Ensino", de Roque Ismael da Costa Güllich. A obra consiste na discussão de três principais enfoques que interagem e se inter-relacionam: o livro, o professor e a formação docente em Ciências. Compreende que processos formativos reflexivos, podem ser uma possibilidade de superação do uso indiscriminado do livro didático bem como sua adoção acrítica no ensino de Ciências. Os caminhos traçados para reconstrução desta relação, tem fundamentação inicial no referencial teórico da investigação-formação-ação e na perspectiva histórico-cultural, tecendo posteriormente novas discussões e compreensões sob a óptica da formação baseada na reflexão crítica. Investiga e analisa o processo formativo/constitutivo de professores de Ciências de escola básica, licenciandos em formação inicial e de professores da Universidade, por meio da abordagem microgenética e do paradigma indiciário. Diante do contexto analisado, do estudo da literatura e a partir das próprias reflexões do autor em relação a relevância da reflexão crítica na formação, este propõe uma ampliação do conceito investigação-formação para investigaçãoformação-ação. $O$ potencial da formação construída em uma perspectiva dialógica, crítica e transformadora, reflete no resgate da autonomia dos docentes dos professores participantes, bem como acredita influenciar a transformação das práticas pedagógicas num constante movimento reflexivo-formativo.
\end{abstract}

Palavras-chave: Investigação-ação, Reflexão crítica, Formação continuada, Currículo.

\begin{abstract}
:
This review deals with the book: "Research-Formation-Action in Science: a Way to Rebuild the Relationship between Didactic Book, Teacher and Teaching", by Roque Ismael da Costa Güllich. The work consists in the discussion of three main approaches that interact and are interrelated: the book, the teacher and the teacher training in Sciences. It understands that reflective formative processes can be a possibility of overcoming the indiscriminate use of the textbook as well as its uncritical adoption in the teaching of Sciences. The paths traced for the reconstruction of this relationship have an initial basis in the theoretical framework of research-formation-action and in the historical-cultural perspective, and later weave new discussions and understandings from the perspective of formation based on critical reflection. It investigates and
\end{abstract}


analyzes the formative / constitutive process of basic school science teachers, undergraduates in initial formation and university teachers, through the microgenetic approach and the indiciary paradigm. Considering the context analyzed, the study of literature and from the author's own reflections on the relevance of critical reflection in training, this one proposes an extension of the research-action concept for researchformation-action. The potential of the formation constructed in a dialogic, critical and transformative perspective, reflects in the recovery of the autonomy of the teachers of the participating teachers, as well as believes influence the transformation of pedagogical practices in a constant reflexive-formative movement.

Key-words: Action research, Critical reflection, Continuing formation, Curriculum.

\section{RESENHA}

Em a Investigação-Formação-Ação em Ciências: um Caminho para Reconstruir a Relação entre Livro Didático, o Professor e o Ensino, Roque Ismael da Costa Güllich, nos apresenta sua tese de Doutorado em Educação nas Ciências, pela Universidade Regional do Noroeste do Estado do Rio Grande do Sul - UNIJUÍ, sendo que o autor é atualmente professor Adjunto da Universidade Federal da Fronteira Sul - UFFS. No livro apresenta as relações do livro didático com o professor e com a formação docente em Ciências, partindo da perspectiva histórica e cultural, bem como dos pressupostos de referenciais da investigação-formação-ação. $\mathrm{O}$ autor como pesquisador da área do Ensino de Ciências e Biologia, articula em sua trajetória como pesquisador, o Educar pela Pesquisa, o Livro Didático, o Currículo e o Ensino de Ciências, visando a inserção dessas temáticas no Ensino de Ciências/Biologia, nas Práticas de Ensino e no Estágio Supervisionado de Ciências e Biologia e nos processos de formação inicial e continuada de Professores.

$\mathrm{Na}$ introdução de sua obra apresenta o propósito de espiral reflexiva de sua pesquisa, entendo-a como um movimento que propicia, sobretudo reflexão no contexto investigativo de uma ação-problema educacional (CARR; KEMMIS, 1988; GÜLLICH, 2013). Justificando a investigação-ação desenvolvida com o forte vínculo entre o Livro Didático (LD), professores da educação básica e a formação de professores de Ciências. Ancorado na velha e ao mesmo tempo atual, dependência do LD para o ensino de Ciências, expressando profunda indignação, com o domínio do mesmo sob a prática docente dos professores, acreditando e partindo do pressuposto de que o LD é 
amplamente, senão exclusivamente usado como aula de Ciências no contexto brasileiro investigado.

A preocupação sobre o tema recai, sobre o fato de haver recorrentes problemas nos LD, como concepções errôneas de Ciências, gerando reproducionismo e passividade. O LD é tido como currículo, como política, como metodologia, como aula e como formação de professores, assim sendo é correto afirmar que ele tem norteado todo o processo de ensino de aprendizagem. Isso, evidência um processo de formação inicial e continuada de professores de Ciências, que deixa de abordar a importância do professor de Ciências saber avaliar, escolher e sobretudo utilizar o LD em classe.

Assim, o autor esclarece que a crítica procedente no atual cenário não é sobre abandonar o LD, mas sobre o seu uso indiscriminado como manual para o ensino e à docência em Ciências. É nesse sentido que a pesquisa foi desenvolvida: "no propósito de compreender um processo formativo continuado [em contexto situado] pela via da reflexão como caminho viável para uma provável melhoria das práticas de ensino em Ciências, demasiadamente aprisionadas pelo uso do livro didático" (GÜLLICH, 2013, p. 26), esta é também a tese objetivada, defendendo que os processos formativos reflexivos e compartilhados na tríade de interação (ZANON, 2003) tornam-se possibilidades para (re)significar a relação entre o professor, o livro didático e o ensino de Ciências. Para isso, foram analisados materiais curriculares, entrevistas, questionários e discursos/diálogos formativos de/entre professores de Ciências, em relação ao LD na sua docência, sendo que na obra, foi descrita a trajetória envolvendo: o processo, a constatação, as mudanças no contexto de formação e os novos e outros problemas, minuciosamente apresentados e discutidos em 4 capítulos.

O autor inicia a sua discussão em capítulos, com uma epígrafe sintetizadora das discussões estabelecidas, reconhecendo que

[...] já fui como uma traça devoradora de livros (didáticos); eu já me alimentei das gravuras e páginas amarelas de muitos livros que visitei, dos quais senti seu cheiro, seu gosto e percebi seus detalhes; eu tive a triste visão ingênua de que este aparato todo favoreceria minha aula de Ciências; o "meu livro queres ler?"; eu já me afoguei de vez nos livros didáticos e me deixei prescrever pelas lindas palavras que lá encontrei; ah, que "belas mentiras"!; "mentiras que parecem verdades"; adotei essas mentiras, sim, porque o professor parece adotar o livro didático; e então fiz o caminho de volta, neguei os livros, suas histórias, seu uso, suas intenções; fiz a crítica ao seu enredo, tentei fazer uma verdadeira fogueira inquisitiva com livros didáticos, porque afinal de contas é o "livro que adota o professor"; e "entre anjos e 
demônios", "medos e ousadias"; estou procurando "o caminho do meio"; tentando compreender como a reflexão na formação pode contribuir para (re)situar minhas próprias compreensões... (GÜLLICH, 2013, p. 31).

A partir de então no capitulo 1, intitulado de "Pesquisar o livro didático e a formação de professores em Ciências: sobre como as coisas aconteceram”, o autor introduz a temática, revisando a literatura da área, descrevendo com propriedade o percurso investigativo trilhado, para melhor desvendar as reais relações, que tecem a problemática sobre as relações entre o LD, o professor e ensino de Ciências. Dando início com uma revisão do estado da arte a respeito do LD, considerando as influências de pesquisas nacionais e internacionais sobre a temática e apresentando ainda $\mathrm{o}$ referencial teórico metodológico que subsidiou a realização da investigação-ação. Neste capítulo, o autor demonstrou também que a sua trajetória profissional, o levou a (re)conhecer e se apropriar verdadeiramente do seu objeto de estudo (LD), desvendando por meio da atuação docente, da gestão e de processos de ação-reflexão-ação de formação inicial e continuada, a discreta, mas frequente presença do LD como articulador dos currículos, dos discursos educacionais e dos processos de ensino e de aprendizagem em Ciências.

Assim, percebeu, que apenas o discurso dos próprios professores de Ciências, em pleno exercício da docência, poderia auxiliar a compreender a relação do livro didático com o professor de Ciências e o processo de formação de professores. Dessa forma, desenvolveu uma pesquisa qualitativa em educação, para investigar o discurso de professores de Ciências, em espaços formativos, utilizando como ambiente e contexto de pesquisa o processo de implementação/criação e as discussões do Grupo de Estudos e Pesquisas em Ensino de Ciências e Matemática (GEPECIEM), constituído por professores de Ciências em formação inicial, professores de Ciências e Matemática em formação continuada e professores supervisores de escola básica, bem como por professores formadores de Ciências e Matemática da Universidade. Ainda discorre, sobre o perfil dos participantes do grupo, as atividades formativas realizadas no mesmo e as questões éticas envolvidas para a realização da pesquisa, bem como os eixos propulsores que surgiram no processo de intervenção proporcionado pela investigaçãoação, são espirais e ciclos formativos dentro da espiral, que permitiram o avanço nas compreensões sobre a temática. Importante frisar que estes movimentos investigativos formativos deram o nome também a ação de extensão do GEPECIEM que em 2018 
completou 8 anos de trabalho, como sendo um Programa denominado: Ciclos Formativos no Ensino de Ciências e Matemática.

O segundo capítulo, intitulado de "O livro didático e o professor de Ciências: amarras discursivas", o autor destina a contar como se dá a relação do professor com o LD, tendo como ponto de partida, as políticas públicas nacionais educacionais curriculares, o currículo escolar e o discurso educacional de professores de Ciências. E percebeu: "uma complexa rede de amarras discursivas que vem tornando o professor potencialmente dependente do livro na execução de seus planejamentos, na organização do currículo escolar, na sua própria formação e no estudo de conceitos" (GÜLLICH, 2013, p.76). Considera, portanto, que as políticas públicas nacionais e as amarras discursivas de todas as partes (editoras, governo, instituições de gestão escolar e universitária, professores), impõe sobre o professor um currículo engessado, aprisionando o ensino e o fazer em Ciências.

O autor, ainda apresenta dados, apontando a aplicação de recursos na compra, avaliação e distribuição dos livros didáticos no Brasil. Discute e defende, a avaliação dos LDs, a escolha com auxílio do Guia do Livro Didático e o uso adequado deste recurso didático no ensino de Ciências. Diante, do exposto o autor, apresenta o dilema: como será possível reconhecer o currículo como estratégia, como identidade, como recontextualização?!. Mas aposta também e defende um caminho/possibilidade, firmada na fundamentação de programas qualificados de formação inicial e continuada de professores que no diálogo formativo, nas trocas de experiências, e, por meio de escritas reflexivas podem se tornar um caminho possível, mas uma melhor formação e transformação das práticas de ensino de Ciências. Todavia, Güllich (2013, p. 142) esclarece, que embora exista uma "relação de aprisionamento do professor de Ciências pelo livro didático e [a própria] formação", pela via reflexiva, podemos perceber a construção de "um caminho possível para o enfrentamento dessa relação".

Já no terceiro capítulo intitulado de: "No contexto da constituição dos professores de Ciências (re)conhecendo concepções, práticas e movimentos formativos", o autor, tem como objetivo discutir os processos formativos, transcorridos no processo da investigação-formação-ação desencadeada no GEPECIEM. Para isso, o autor se preocupa em abordar detalhadamente os momentos formativos, sistematizando os mesmos, em episódios, pormenorizados em turnos que demonstram as minúcias do 
processo desenvolvido. Para tanto, lança mão do paradigma indiciário e da análise microgenética (GÓES, 2000) amalgamados na perspectiva Histórico-Cultural de Vigotski (2001) para melhor explicar os processos constitutivos dos sujeitos envolvidos no processo de formação investigado. Cada, episódio representa um processo formativo, sendo mediado/intencionado pela discussão, investigação e reflexão de uma problemática relacionada ao ensino de Ciências. Esses momentos/movimentos formativos, permitiram o autor, identificar, analisar e discutir as concepções dos professores de Ciências, observando as limitações e idealizações dos sujeitos envolvidos, evolução conceitual dos mesmos e a (re)significação do processo de formação a que estavam envolvidos e da relação entre professores, livros didáticos e o ensino de Ciências, sempre tendo a reflexão como articuladora do processo formativo.

No quarto e último capítulo da obra, "A reflexão crítica como mediadora da formação de professores de Ciências: a Investigação-Formação-Ação", é abordada a pesquisa e a formação de professores, tendo a reflexão com precursora e mediadora do processo de investigação-ação, o qual é apontado como um caminho transformador das práticas docentes. Emergindo dos resultados obtidos com a discussão conjunta dos episódios realizados, se aborda a perspectiva da Investigação-Ação, momento em que o autor faz um esforço teórico para avançar no conceito recolando a reflexão crítica como marca do processo formativo, expandindo este conceito para Investigação-FormaçãoAção, como um processo que de fato é capaz de transformar ações. Estabelecendo inicialmente uma crítica, sobre como a formação de professores de Ciências, tem se configurado tecnicista e tradicional. Em seguida, apresenta fortes indícios de como a reflexão é uma mediadora, do processo de constituição de professores, considerando a mesma como uma categoria integrada a investigação-ação, quando se deseja formar professores. Aponta e discute detalhadamente indícios de transformação/mudança na prática docente dos professores participantes do processo formativo, como por exemplo: mudanças de atitude; relação entre o LD e os professores; interações; autonomia; escrita reflexiva, diálogo formativo e reflexão entre outros indícios de transformações, com a Investigação, Formação e Ação de seu Ser Professor.

Ao concluir, é retomada a ideia de espiral autorreflexiva proposta no início da obra e ao dar a volta no ciclo reflexivo, o autor faz um novo olhar sobre e para o tema e reafirma que por meio da reflexão compartilhada, se abre um caminho possível à 
melhoria das práticas de "ensino de Ciências, contribuindo para o enfrentamento da relação de aprisionamento que o livro didático exerce sobre os professores" (GÜLLICH 2013, p. 295). Ao finalizar o livro, sinaliza que, as discussões elucidadas no GEPECIEM, possibilitaram identificar que os professores inicialmente usavam o LD, de acordo ao contexto, utilizando os mesmos como suas próprias aulas, como metodologia ou até mesmo como o currículo em si, mas com o passar das discussões e reflexões promovidas no grupo, "os professores passaram de 'seguidores do livro' para condição de autores de um currículo" (GÜLLICH, 2013, p. 296). Nesta parte o autor aborda ainda, que esses processos formativos instigaram os professores a se (re)inventar, sendo que algumas professoras, tornaram-se supervisoras de projetos, outros ingressaram em especializações, mestrado e doutorado. Estes efeitos, são considerados como sendo o resultado, de todos os desafios propostos aos professores, como o de escrever em diários de bordo para reflexão de suas práticas, escrita de relatos de experiência para socialização com os demais, troca ideias e compartilhamento de ações. Contudo, específica que a transformação das práticas, depende além de formação de professores, da transformação da realidade escolar como um todo, chegando a sugerir que as escolas precisam ser comunidade autorreflexivas para propositar estas transformações maiores desde as escolas. Expressando ainda, que a pesquisa proporcionou transformações das concepções de prática e teoria, em relação a constituição de uma aprendizagem significativa sobre a formação de professores de Ciências.

Assim, aponto que a obra tratou de modo profícuo o tema exposto, foi bem elaborada, escrita e discutida. Sendo, que aborda amplamente os aspectos relacionados ao ensino de Ciências, levando em consideração a raiz das problemáticas no ensino, até a profunda análise teórica e prática das amarras da docência, trazendo assim uma proposta de ensino inovador, dinâmico, flexível e contextual. A obra em si, bem como a leitura do texto é um convite ao estudo e a pesquisa. A meu ver, livro serve de subsídio para professores em formação inicial na área das Ciências, para que compreendam a importância da reflexão, pesquisa, investigação e discussão para sua constituição como professor; para professores em atuação, para que consigam ver possibilidade de inovação, por meio da reflexão de suas práticas; para professores coordenadores de projetos e programas de formação de professores de Ciências como subsídio para 
elaboração de programas de formação; para coordenadores e professores de curso de Ciências Biológicas, Química e Física para reorganização curricular desde o contexto escolar; para professores formadores mestres e doutores como fonte de pesquisa e aprofundamentos de temas e, bem como a geração de novas temáticas; e ainda a leitura é indiada para estudiosos/pesquisadores, na área da educação em geral, visto que a obra apresenta muitas contribuições para o avanço dos estudos na temática, oxigenando a agenda de pesquisa sobre o livro didático.

Reforço o convite a leitura, com as palavras colocadas no prefácio do livro, pela orientadora da Tese de Doutorado Lenir Basso Zanon, onde a mesma afirma que "a leitura do livro enseja possibilidades de concretização de mudanças nas/das práticas educativas fundadas na potencialidade da abertura para saber lidar com o outro (diversidade)", ressaltando ainda que "essa mudanças são apostas e desafios inerentes a cada um que se diz professor e cada uma que se diz professora".

Destaco ainda, que a obra é finalizada com agradecimentos aos participantes da pesquisa e chamando o contexto de campo fértil como qual trabalhou e - em démarche, ou seja, em movimento, apontando outras possibilidades/flancos de aprofundamento possíveis para a temática e abrindo possibilidades para novas e outras interpretações.

\section{REFERÊNCIAS}

CARR, W; KEMMIS, S. Teoria crítica de la enseñanza: investigación-acción en la formación del profesorado. Barcelona: Martinez Roca, 1988.

GÜLLICH, R. I. C. Investigação-Formação-Ação em Ciências: um Caminho para Reconstruir a Relação entre Livro Didático, o Professor e o Ensino. Curitiba: Prismas, 2013.

GÓES, Maria Cecília Rafael de. A abordagem microgenética na matriz históricocultural: Uma perspectiva para o estudo da constituição da subjetividade. Cadernos Cedes. São Paulo, abr. 2000. p. 9-25. Disponível em: <http://www.paulorosa.docente.ufms.br/metodologia/Goes_Analise_microgenetica.pdf> . Acesso em: 04 fev. 2019.

VIGOTSKI, L. S. A construção do pensamento e da linguagem. Tradução Paulo Bezerra. São Paulo: Martins Fontes, 2001. 
ZANON, L. B. Interações de licenciandos, formadores e professores na elaboração conceitual de prática docente: módulos triádicos na licenciatura de Química. 2003. 201 f. Tese (Doutorado) - Curso de Faculdade de Ciências Humanas, Universidade Metodista de Piracicaba, Piracicaba, 2003. 